\title{
UTILITIES AND LIMITATIONS OF CURRENT ANIMAL MODELS OF DEPRESSION
}

\author{
ANDY RAMJATTAN ${ }^{1}$, PINTO PEREIRA LEXLEY M. SAMEER DHINGRA ${ }^{2 *}$
}

${ }^{1}$ Department of Paraclinical Sciences, Faculty of Medical Sciences, The University of the West Indies, St. Augustine Campus, Trinidad and Tobago. ${ }^{2}$ School of Pharmacy, Faculty of Medical Sciences, The University of the West Indies, St. Augustine Campus, Trinidad and Tobago. Email: sameer.dhingra@sta.uwi.edu

Received: 18 June 2017, Revised and Accepted: 26 August 2017

ABSTRACT

Depression is one of the most debilitating medical conditions in the world today, yet its etiologies remain imprecise, and current treatments are not wholly helpful. Depression is more than just a feeling of sadness. Depression can affect the daily routine of an individual disrupting work, play, and overall ability to concentrate. People with depression usually experience a lack of interest and enjoyment in daily activities, notable weight loss or gain, sleeplessness or excessive sleeping, lack of energy, inability to concentrate, feelings of worthlessness or shame, and recurrent thoughts of suicide (diagnostic and statistical manual-V). It is projected to be the second leading cause of disability worldwide by 2020. It is estimated that depression currently affects 350 million people from around the world. There are a number of drugs of different pharmacological classes being used in the treatment of clinical depression. Animal models are indispensable tools in the search to identify new antidepressant drugs and to provide insights into the neuropathology that underlies the idiopathic disease state of depression. Animal models of depression can be used for a variety of purposes, including use as a tool for investigating aspects of the neurobiology and pathophysiology of depression, as an experimental model for studying the mechanism of action of antidepressant drugs and for screening antidepressant activity. None of existing animal models currently fulfil the existing criteria for an ideal animal model, and therefore, demands an insight view of the existing models of depression. This article attempts to review the most widely used animal models and highlights their important features with respect to different pharmacological classes of antidepressant drugs.

Keywords: Animal models, Depression, Behavioral models, Chemical models, Forced swim test, Tail suspension test.

(c) 2017 The Authors. Published by Innovare Academic Sciences Pvt Ltd. This is an open access article under the CC BY license (http://creativecommons. org/licenses/by/4. 0/) DOI: http://dx.doi.org/10.22159/ajpcr.2017.v10i12.20811

\section{INTRODUCTION}

Depression affects more than $20 \%$ of the world population, is currently the fourth leading cause of disability worldwide [1], and is projected to be the second leading cause of disability worldwide by the year 2020 [2]. It can manifest as any of the symptoms described by the Diagnostic and Statistical Manual of Mental Disorder V (DSM 5) [3]. Depression can affect anyone and can lead to both mental and physical alterations in an individual. Mood changes such as sadness, hopelessness, feeling down, emptiness, irritability, withdrawal from daily activities, inability to gain pleasure, restless, and feeling of guilt or recurring thought of death can be experienced by a depressed individual. There are a few other changes such as alteration in sleep patterns, weight gain or loss, change in appetite, and inability to concentrate can also occur. It is estimated that depression currently affects 350 million people worldwide, and this number is increasing and for which little is known. It is estimated that approximately 1 trillion USD is spent on depression annually.

\section{SYMPTOMS OF DEPRESSION}

Depression, also known as major depressive disorder (MDD), is characterized as one or more depressive episodes without a history of manic, mixed, or hypomanic episodes. It can be expressed as emotional, physical, cognitive, or psychomotor symptoms. Emotional symptoms include loss of interest in daily activities, sadness, hallucinations, hopelessness, and feelings of guilt. Physical symptoms include weight loss or gain, appetite disturbance, sleep disturbances, pain, or GI and cardiovascular complications. Cognitive symptoms include problems concentrating, disturbance in remembering, indecisiveness, and confusion. Psychomotor symptoms include slowed movement, thought process, and slowed speech.

Depression may be a secondary disease due to conditions such as infection, for example, sexually transmitted disease, neurological disorders (epilepsy, pain, or Alzheimer's disease), withdrawal for substance abuse or cancer. There is currently no definite known cause of depression, and most of the current etiology is based on various hypotheses. The biogenetic amine hypothesis is based on depression being caused by a decrease in brain levels of specific neurotransmitters such as norepinephrine, serotonin, and dopamine [4]. The postsynaptic change in receptor sensitivity studies the desensitization of receptors to norepinephrine or serotonin. The deregulation hypothesis is based on the failure of neurotransmitter systems as opposed to increase or decrease in activity. The serotonin-norepinephrine hypothesis is based on a proposed link between the two neurotransmitters, and both are involved in depression. The dopamine hypothesis suggests that the decrease in dopamine in the mesolimbic pathway is a cause for depression.

\section{DIAGNOSIS OF DEPRESSION}

Depression can be characterized by one or more of the criteria from the Diagnostic and Statistical Manual of Mental Disorder 5 (DSM-5). For a person to be diagnosed as being depressed, they should experience the symptoms for more than 2 weeks and does not include symptoms brought on by another medical condition or medication. Table 1 lists the DSM 5 criteria for MDD. Five (or more) of the following symptoms have been present during the same 2 -week period and represent a change from the previous functioning; at least one of the symptoms is either (1) depressed mood or (2) loss of interest or pleasure.

\section{TREATMENT OF DEPRESSION}

Depression can be treated with pharmacological or nonpharmacological treatments. Cognitive therapy, behavioral therapy, interpersonal psychotherapy, electroconvulsive therapy, and bright light therapy comprise of nonpharmacological therapy and are only used in mildto-moderate severity as first-line treatment. The pharmacological treatment consists of various classes of medication such as selective reuptake inhibitors, serotonin/norepinephrine reuptake inhibitors, 
aminoketone, triazolopyridines, tetracyclic, tricyclics, and monoamine oxidase inhibitors [5]. Each of these classes is associated with one or other side effect. Table 2 shows the side effects associated with different classes of antidepressants. There can be instances where nonpharmacological therapy is combined with pharmacological therapy such as the use of ECT with drug treatment for psychotically depressed individuals.

\section{ANIMAL MODELS}

Animal models have been used for years as a vital tool to screen products before they are deemed safe for humans. Animals are sometimes used in the screening of drugs, testing of vaccines and other biologically modified serum, and medical devices, mainly to determine the safety (pros and cons) of the medicinal product. For drugs and biologics, the focus of animal testing is on the drug's nature, chemistry, and the effects (pharmacology) and on its potential damage to the body (toxicology) [6].

\section{REQUIREMENT FOR AN IDEAL ANIMAL MODEL}

It is proposed that the minimal requirements for an ideal animal model of depression include (a) be reasonably analogous to the human disorder in its symptomatology (face validity), (b) cause behavioral changes that can be monitored objectively, (c) produce changes that are reversed by the same treatment modalities that are effective in humans (predictive validity), and (d) should be reproducible between investigators. An ideal animal model of depression should fulfil the abovementioned criterion as much as possible [7].

\section{ANIMAL MODELS OF DEPRESSION}

Animal models of depression are widely used to screen antidepressants for different purposes such as a tool for investigating aspects of neurobiology and pathophysiology of depression, as experimental models for studying the mechanism of action of antidepressants and for screening antidepressant activity. Animal models of depression can be categorized into being behavioral, chemical, or genetic models.

\section{BEHAVIORAL MODELS OF DEPRESSION}

\section{Forced swim test (FST)}

The FST is one of the simplest and most commonly used animal models used in screening antidepressants. The FST would require a large cylinder ( $40 \mathrm{~cm}$ height by $18 \mathrm{~cm}$ diameter) [8], water, a thermometer, a stopwatch, a camera to record the procedure, the rats, and a laboratory which temperature can be adjusted. The FST is based on the premise that, when the rats are placed in an inescapable situation, they are forced to swim to keep their head above the level of water. The carrying out of the procedure entails the cylinder being filled with a specified amount of water and the temperature of the water set at $25^{\circ} \mathrm{C}( \pm 2)$ [9]. The cylinder is deep enough as not allow the hind legs of the rats to touch the bottom of the cylinder and sufficient to not allow it to escape at the top. Results are taped and reviewed at a later time for which there are two ranks which are swimming and climbing (active) and immobilized (passively). Under normal condition, the rats give up and assume the passive phase, and when given an antidepressant, the time which it takes for the rats to go to the passive stage is prolonged. Antidepressants can, therefore, be seen to increase the active stage. The advantages of the FST are that it is sensitive to most antidepressants, it is easy to perform, and it is highly reproducible which allows for low cost and high amount of test to be carried out over a short time. Some of the drawbacks are that it is only sensitive to acute treatment, there is the risk of hypothermia, it is not specific to nonmonoamine antidepressants, and it is not specific to selective serotonin reuptake inhibitor (SSRIs). The major drawback of the FSH is that it is unreliable in the detection of the effects of SSRIs and false-positive results are induced by opiates and anti-histamines (Fig. 1).

\section{MODIFIED FST}

The modified FST is an upgraded version of the FST with a few changes in the procedure such as a change in the depth of the water in the cylinder to $30 \mathrm{~cm}$ from 15 to $18 \mathrm{~cm}$ and sampling behavior every 5 seconds [10]. These minor adjustments allow for the investigator to easily distinguish between the active and passive states. The major

\section{Table 1: DSM-V criteria for MDD}

Depressed mood or a loss of interest or pleasure in daily activities for more than 2 weeks

Mood represents a change from the person's baseline.

Impaired function: Social, occupational, educational.

Specific symptoms, at least 5 of these 9 , present nearly every day

Depressed mood or irritable most of the day, nearly every day, as indicated by either subjective report (e.g., feels sad or empty) or observation made by others (e.g., appears tearful)

Decreased interest or pleasure in most activities, most of each day

Significant weight change $(5 \%)$ or change in appetite

Change in sleep: Insomnia or hypersomnia

Change in activity: Psychomotor agitation or retardation

Fatigue or loss of energy

Guilt/worthlessness: Feelings of worthlessness or excessive or inappropriate guilt

Concentration: Diminished ability to think or concentrate, or more indecisiveness

Suicidality: Thoughts of death or suicide, or has suicide plan

MDD: Major depressive disorder

Table 2: Side effects associated with the different classes of antidepressants

\begin{tabular}{|c|c|c|c|c|c|c|c|}
\hline Side effects & SSRI & TCA & SNRIs & NARI & NaSSA & MAOI & RIMA \\
\hline GI distress & +++ & $0 /+$ & +++ & $0 /+$ & $0 /+$ & $+/++$ & + \\
\hline Sexual disturbance & +++ & ++ & +++ & $0 /+$ & 0 & $+/++$ & 0 \\
\hline Weight gain & $0 /+$ & ++ & 0 & 0 & +++ & + & 0 \\
\hline Dermatitis, rash & $0 /+$ & + & 0 & $0 /+$ & 0 & 0 & 0 \\
\hline CNS effects (sedation fatigue) & $+/+++$ & $++/+++$ & + & + & +++ & $+/++$ & + \\
\hline Anticholinergic effects (dry mouth, tremor) & + & $++/+++$ & + & + & ++ & ++ & + \\
\hline ECG changes (tachycardia) & 0 & ++ & 0 & $0 /+$ & 0 & + & 0 \\
\hline Hypertension & 0 & 0 & ++ & + & 0 & ++ & 0 \\
\hline
\end{tabular}

SSRI: Selective serotonin reuptake inhibitor, TCA: Tricyclic antidepressant, NARI: Noradrenaline reuptake inhibitors, NaSSA: Noradrenaline specific serotonin reuptake

inhibitors, MAOI: Monoamine oxidase inhibitor, RIMA: Reversible monoamine oxidase inhibitor, CNS: Central nervous system, ECG: Electrocardiography,

SNRI: Serotonin -noradrenaline reuptake inhibitor 
advantage unlike its predecessor is now able to detect SSRIs. It still, however, has the drawback of the risk of hypothermia, its validity for nonmonoamine antidepressants is uncertain, and it is limited to its only sensitive for acute treatments. It has predictive validity and is easy to perform.

\section{TAIL SUSPENSION TEST (TST)}

The TST was developed as a rodent screening test for potential (human) antidepressant drugs. The materials need for this test is very simple (a metal rod, tape, and a camera to record the results and mice) and is easy to perform. The mice are suspended upside down from the metal rod and monitored. It is based on the assumption that when the mice are placed in an escapable situation (struck by the tail) they would try to escape. The subjects leave for 5 minutes as an observational period after which results are recorded [11]. The TST, such as the FSH, has two movements which are the thrashing about to escape (active) and no movement or attempt to escape (passive). The passive state is seen as the depressed phase, and the prolongation of the active phase can be achieved by the use of antidepressants [12]. The advantages of the TST are its sensitive to antidepressants, have predictive validity, has high reproducibility, is easy to perform, and allows for high throughput at a low cost. Its disadvantages are that it only sensitive to acute treatment, its validity for certain nonmonoamine antidepressants are uncertain, is not applicable in rats and applicable in only certain mouse strains (Fig. 2).

\section{LEARNED HELPLESSNESS MODEL (LHM)}

When placed into an uncontrolled stressed situation over time from where there is no escape subject exhibit a depressive state, this is the basis on which the LHM was formed [13]. The test is composed of a two-compartment box separated with the route to unelectrified side escape chamber closed. A constant current of shocker delivering 60 scrambled shocks (15 seconds duration, $0.8 \mathrm{~mA}$ every minute) [14] through the steel grid floor. There are two types which are the inescapable shock treatment and the conditioned avoidance training. In the inescapable shock treatment, the experiment is repeated on day 3 (48 hrs) [15]. In the conditioned avoidance training, the rodents learn to avoid unpleasant stimuli by performing the appropriate response to protect itself. However, there is a difference between rats and mice, the lever press method is applied to rats, and the shuttle box is used for mice. The subjects usually exhibit depressed states in one or several days with repeated exposure to the stimuli. This LHM subject can be selectively bred to a control group and offspring showing two traits
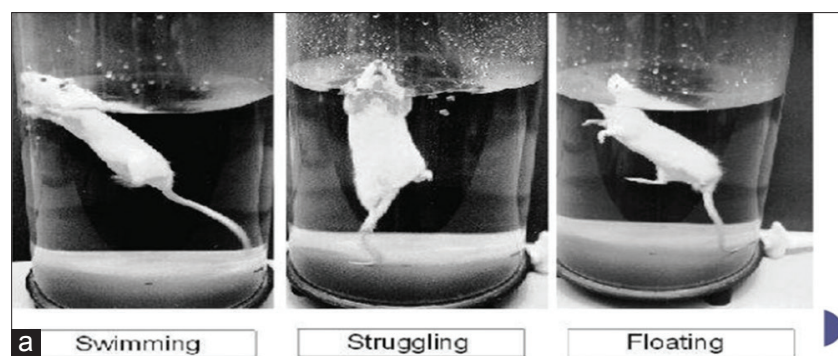

Fig. 1: (a-c) Different behaviors of an animal during forced swim test
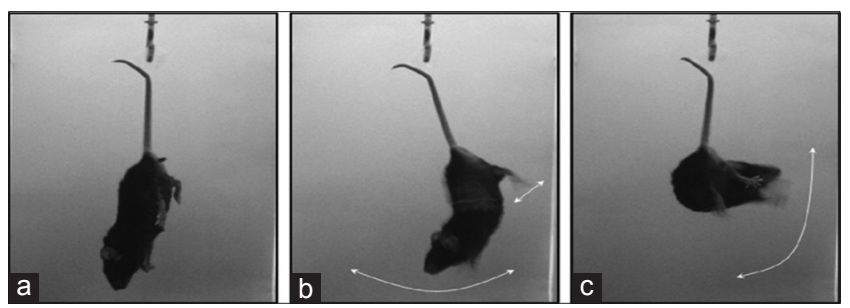

Fig. 2: (a-c) Different postural movements during the tail suspension test with some showing LH and some resistant to LH [16]. The LHT has the advantages of predictive validity, including alterations in HPA axis activity and no false negatives. The disadvantages are that it is sensitive to some antidepressants, sensitive to acute treatment specificity is questionable, it requires very stress, it is time consuming, there are ethical restrictions, and it is difficult to replicate [17].

\section{OLFACTORY BULBECTOMY}

As the name implies, the olfactory bulbs are removed and the rats exposed to stressful situations. This experiment usually has a test and a controlled group. The olfactory system in rats is part of the limbic region amygdala and hippocampus forms a part of the emotional and memory of behavior. It is not only the removal of the olfactory bulb alone that is solely responsible for the behavioral changes but also causes a dysfunction in hippocampal-amygdala circuit which causes the behavioral changes [18]. This test is not only used alone but also is used in conjunction with other animal models such as open-field and passive avoidance test. The advantage of the olfactory bulbectomy is that it is specific for all antidepressants and has face validity. Its disadvantages are as follows: It is difficult to reproduce, some antidepressants show effects only after subchronic treatment, and the effects are variable for different antidepressants [19].

\section{SOCIAL DEFEAT (SD)}

SD is based on the principle that loss of rank of a previously dominant rat (or human) is associated with a loss of self-esteem, and a loss of self-esteem has been associated with depression. This test is carried out by introducing a highly aggressive experimental group to a resident group and both allowed to interact [20]. The intruder (experimental) group is rapidly investigated and defeated. The resident group usually is given the advantage of having a higher body weight, making them more likely to overcome the experimental group. After a few minutes of interaction, both groups are separated by a divider made of plastic with holes allowing for auditory, visual, and olfactory interaction for 24 hrs [21]. This interaction is usually repeated to different resident groups, at the end of each, one group is dominant (resident) and one being subordinate (experimental). Two outcomes are tested in the experimental group which are reduced preference for a sweet solution (reward-based sucrose preference [RBSP] model) and social avoidance in the presence of an unfamiliar animal $[19,22,23]$. Changes in behavioral or psychological changes include decreased sexual behavior, increased anxiety, changes in circadian rhythm (sleep changes), alterations in body weight, and impaired immune function. This test is sensitive to chronic administration to antidepressant, and behavioral changes are usually long lasting. SD has constructed and predictive validity but is difficult to reproduce [24].

\section{CHRONIC MILD STRESS (CMS)}

CMS sometimes described as chronic unpredictable stress involves the use of a stress over a prolonged period of time [23]. The use of CMS is applicable since it develops a depressed state that gradually over time. The changes are both physical and emotional, and since it is difficult to properly access, emotional stress measurement is done through the RBSP [25]. Repeated use of the same stress rats usually develops adaptations to cope, but the CMS uses stress in an unpredictable sequence. The usual depressed state can be reversed by the use of chronic antidepressant administration applied either during or after the stress period. This model has poor reproducibility, some groups have had consistently produced depressed rats, and others have not experienced the same reliability. The CMS model has good predictive validity (behavioral changes are reversed by chronic treatment with a wide variety of antidepressants) [25,26], face validity, and construct validity (CMS causes a generalized decrease in responsiveness to rewards, comparable to anhedonia, the core symptom of the melancholic subtype of MDD). It also provided insights into molecular alteration in depression. The disadvantages are that it is difficult to reproduce, is time consuming, requires a lot of workspace, and is labor intensive sounds good. 


\section{EARLY LIFE STRESS (ELS)}

Exposure to stress at an early stage has been known to increase the risk of depression in individuals. Traumatic experiences (such as loss of a parent, childhood illness, family violence, deprivation of basic necessities, and any type of abuse) have repercussions in adulthood leading to psychiatric consequences. The ELS model [27] is based on the uses of stress at critical early points in the development of subject to cause phenotypic changes. There can be neurochemical, endocrine, and behavioral changes occurring due to the ELS model which predisposed individual to depressive illness. Construct validity of ELS models will depend on phenotyping of the animals.

\section{MATERNAL SEPARATION (MS) MODEL}

As mentioned above, the use of ELS can be used as a stress to initiate depression in an individual. MS is used as the means by which stress is applied to a subject. This usually entails the offspring being separated from their mother for 3.6 hrs during the first 2 postnatal weeks [18,28-30]. These individuals are allowed to develop under normal conditions, and at adulthood, phenotypic characteristics are evaluated. This model usually has good construct and predictive validity. The change due to the MS is usually analogous to depression, neurological changes, and allows for the model to be useful in detecting gene expression and mechanisms related to mood disorders $[31,32]$. It is also said to have face validity due to its ability to show parental depression and is done during the critical development of the offspring.

\section{PRENATAL STRESS MODEL}

Maternal stress can cause a number of altered neurological changes in offspring [33]. This test is unpredictable since not all the offsprings are affected and those that are affected occur in different ways. The use of noise disturbance during pregnancy can have outcomes such as anxiety and depression in offspring as well as alterations in HPA axis [34]. The MS model has construct and face validity, but it can sometimes be difficult to distinguish stress occurring prenatally and postnatal.

\section{GENETIC ANIMAL (GM) MODELS}

There are been links between genetic factors, and depression GM animals are currently being used in models for brain pathologies such as anxiety and depression [35]. Science has allowed for the manipulation of gene expression either by over-expressing or underexpressing glucocorticoid receptors. By controlling, the expression of genes offspring can be hardwired as depressed and test carried out to further explore the mechanisms of depression [36]. Adrenergic receptor knockout mice, glucocorticoid receptor heterozygous mice, and cAMP response element binding protein over expressed mice are some examples of genetically modified animals of depression.

\section{CHEMICAL ANIMAL MODELS}

\section{Sucrose preference test (SPT)}

Subjects are born with an innate preference for sweet food, the sucrose preference uses this innate preference, and those subjects with a decreased liking for it can be deemed as depressed. The SPT [37] is used as in indicator of anhedonia (lack of interest in rewarding stimuli), which is present in some forms of affective disorder, including depression. Reduction in preference for sucrose in the SPT represents anhedonia, while the reduction can be reversed by the treatment with antidepressants [38]. The mice are presented with two tubes (one with water and the other with sucrose), and the amount used each day is measured and recorded.

\section{Reserpine reversal}

Reserpine irreversibly blocks the vesicular monoamine transporter which is responsible for the transport of intracellular neurotransmitters norepinephrine, serotonin, and dopamine. The reserpine model is based on the capability of antidepressants to reverse the inhibitory effects of reserpine on motility (catalepsy), body temperature (hypothermia), and ptosis (eye closure) antagonism in rats and mice [39-41]. The reversal of ptosis and hypothermia by pre-treatment with tricyclic antidepressant (TCA) and monoamine oxidase inhibitors is established and was the first clear demonstration of a difference in pharmacological activity between TCAs [42]. To identify compounds that enhance synaptic concentration of serotonin, the test detects elevated levels of serotonin by measuring the potency to further increase the behavioral syndrome induced by administration of 5-hydroxytryptamine receptor (5-HTP) [43-45], which is the metabolic precursor of 5-HT. The test provides a rapid and accurate index of SSRI $[13,46]$ potency in vivo. Animals with lower levels of 5-HT1A auto receptors are more resilient to repeated exposures of forced swim stress compared to animals with higher levels of auto receptors. The advantage of the reserpine reversal model is that it has good predictive validity.

\section{AMPHETAMINE WITHDRAWAL}

Exposure to methylphenidate (MPH) or cocaine in preadolescence affected behaviors in adult rats. MPH is a stimulant prescribed for the treatment of attention-deficit/hyperactivity disorder. Stimulant drugs can cause enduring behavioral adaptations, including altered drug sensitivity, in laboratory animals. Exposure to MPH in preadolescence can cause behavioral changes in adulthood, including finding cocaine less rewarding and demonstrating depressive-like symptoms [47]. Amphetamine withdrawal resulted in a prolonged (5 days) deficit in brain reward function as assessed by elevations in intracranial self-stimulation thresholds. Animals treated with a high dose of amphetamine (10 mg/kg/day) exhibited increased climbing behavior and decreased immobility 24 hrs after withdrawal; by the 48-hrs testing time point, this effect had dissipated [48]. In the mouse TST, both regimens of amphetamine pre-treatment induced increases in immobility scores, also indicative of "depressive-like" behavior.

\section{RETINOIC ACID DERIVATIVES}

Retinoic acid is a derivative from the metabolism of Vitamin A. Retinoic acid is used by the human body for growth and development. It acts by binding to retinoic acid receptors (RAR) and causes a conformational change in deoxyribonucleic acid. It is used both topically and orally to treat acne but carries the risk of depression, suicide, and psychosis [49]. Isotretinoin, a retinoic acid, currently being used to treat severe acne and has been associated with an increased risk for depression and suicide. Mice chronically treated with it shows an increase in the FST and TST passive phase, which can be seen to induce depression-like symptoms $[18,50]$. RARs which are numerous in the brain belong to the nuclear hormone receptor family of transcription factors, and the transcriptional consequences of isotretinoin exposure within limbic brain regions remain unexplored (Table 3 ).

\section{CONCLUSION}

Animal models have been able to show the greater predictive validity and have been used to demonstrate depression in animals. Although there is no single animal model that exists today to replicate all the aspects of depression, they show a great deal of importance in various aspects of the multifaceted disease depression. The most commonly used models are the FST and TST due to them being easy to perform and ease of collecting data for multiple test subjects over a short time period. Animal models vary from simple to very complex ones which require more time to carry out. Due to depression being complex, it is very difficult for anyone animal model to fully explore the disease as a whole. Apart from their use in the pharmaceutical industry, they can be used to explore new or existing areas of depression. Finally, while clinicians continue to refine novel experimental treatments for depression, basic scientists must complement their efforts by exploring the neurobiological mechanisms underlying those treatments; such translational approaches will further narrow the gap between human depression and the theoretical formulations of its mechanisms. 
Table 3: Salient features of animal models of depression

\begin{tabular}{|c|c|c|c|c|}
\hline Name & Validity & Reproducibility & Advantages & Disadvantages \\
\hline \multirow[t]{5}{*}{ FST } & \multirow[t]{5}{*}{ Predictive } & \multirow[t]{5}{*}{ Easy } & Sensitivity to antidepressants & Sensitive to acute treatment only \\
\hline & & & Easy to perform & Validity for nonmonoamine antidepressants \\
\hline & & & High reproducibility & uncertain \\
\hline & & & Low cost & Risk of hypothermia \\
\hline & & & High throughput & Not specific for SSRI \\
\hline \multirow[t]{4}{*}{ Modified FST } & \multirow[t]{4}{*}{ Predictive } & \multirow[t]{4}{*}{ Easy } & Sensitive to antidepressant & Sensitive to acute treatment only \\
\hline & & & Easy to perform & Validity for nonmonoamine \\
\hline & & & Can detect SSRI & Antidepressants uncertain. \\
\hline & & & & Risk of hypothermia \\
\hline \multirow[t]{5}{*}{ TST } & \multirow[t]{5}{*}{ Predictive } & \multirow[t]{5}{*}{ Easy } & Sensitive to antidepressant & Sensitive to acute treatment only \\
\hline & & & Easy to perform & Validity for nonmonoamine antidepressants \\
\hline & & & High reproducibility & uncertain \\
\hline & & & Low cost & Not applicable in rats \\
\hline & & & High throughput & Applicable only in certain mouse strains \\
\hline $\begin{array}{l}\text { Sucrose } \\
\text { Preference }\end{array}$ & Construct & & $\begin{array}{l}\text { Responds to chronic antidepressant } \\
\text { treatment }\end{array}$ & The method is not specific \\
\hline \multirow{5}{*}{$\begin{array}{l}\text { Learned } \\
\text { helplessness }\end{array}$} & \multirow[t]{5}{*}{ Predictive } & \multirow[t]{5}{*}{ Difficult } & \multirow{5}{*}{$\begin{array}{l}\text { Good predictive validity including } \\
\text { alternation in HPA axis activity and REM } \\
\text { sleep characteristic of depression } \\
\text { No false negatives }\end{array}$} & Sensitive to some antidepressants \\
\hline & & & & $\begin{array}{l}\text { Sensitive to acute treatment only and } \\
\text { specificity is questionable }\end{array}$ \\
\hline & & & & Requires very strong stressors \\
\hline & & & & Time consuming \\
\hline & & & & Ethical restrictions \\
\hline \multirow[t]{2}{*}{$\begin{array}{l}\text { Olfactory } \\
\text { bulbectomy }\end{array}$} & \multirow[t]{2}{*}{ Face } & \multirow[t]{2}{*}{ Difficult } & \multirow[t]{2}{*}{ Specific for antidepressants } & $\begin{array}{l}\text { Some antidepressants show effects only after } \\
\text { subchronic treatment }\end{array}$ \\
\hline & & & & $\begin{array}{l}\text { Effects are variable for different } \\
\text { antidepressants }\end{array}$ \\
\hline SD & $\begin{array}{l}\text { Construct and } \\
\text { Predictive }\end{array}$ & Difficult & No data available & No data available \\
\hline Genetic models & Predictive & Difficult & $\begin{array}{l}\text { Endophenotype interaction } \\
\text { Allows for the study of single gene }\end{array}$ & Cannot detect multigenetic disease \\
\hline
\end{tabular}

SD: Standard deviation, SSRI: Selective serotonin reuptake inhibitor, TST: Tail suspension test, FST: Forced swim test

\section{REFERENCES}

1. Rueger S, Malecki C, Pyun Y, Aycock C, Coyle S. A metaanalytical review of the association between perceived social support and depression in childhood and adolescence. Psychol Bull 2016;142(10):1017-67.

2. U.S. Department of Health and Human Services. National Institute of Mental Health NIH Publication No. 15-3561; 2015.

3. Chisholm D, Sweeny K, Sheehan P, Rasmussen B, Smit F, Cuijpers P, et al. Scaling-up treatment of depression and anxiety: A global return on investment analysis. Lancet Psychiatry 2016;3(5):415-24.

4. Chilvers C, Dewey M, Fielding K, Gretton V, Miller P, Palmer B, et al. Antidepressant drugs and generic counselling for treatment of major depression in primary care: Randomised trial with patient preference arms. BMJ 2001;322(7289):772-5.

5. Litwack G, Duman C. Vitamins and Hormones. Vol. 82. New Haven, Connecticut, USA: Elsevier Inc.; 2010. p. 1-270.

6. Holsboer F. The corticosteroid receptor hypothesis of depression. Neuropsychopharmacology 2000;23(5):477-501

7. Wells B. Pharmacotherapy Handbook. Vol.71. New York: McGraw-Hill; 2012. p. 873-92.

8. McGonigle P, Ruggeri B. Animal models of human disease: Challenges in enabling translation. Biochem Pharmacol 2014;87(1):162-71.

9. Porsolt RD, Bertin A, Jalfre M. Behavioral despair in mice: A primary screening test for antidepressants. Arch Int Pharmacodyn Ther 1977;229(2):327-36

10. Cryan JF, Valentino RJ, Lucki I. Assessing substrates underlying the behavioral effects of antidepressants using the modified rat forced swimming test. Neurosci Biobehav Rev 2005;29(4-5):547-69.

11. Steru L, Chermat R, Thierry B, Simon P. The tail suspension test: A new method for screening antidepressants in mice. Psychopharmacology (Berl) 1985;85(3):367-70.

12. Liu X, Peprah D, Howard K, Gershenfeld HK. Tail-suspension induced hyperthermia: A new measure of stress reactivity. J Psychiatr Res 2003;37(3):249-59.

13. Selingman ME, Rosellini RA, Kozack MJ. Learned helplessness in rate: Time course, immunization and reversibility. J Comp Physiol
Psychol 1978;88(2):542-7.

14. Milind P, Dhingra S. A review on animal models of depression. Asian J Bio Sci 2010;5(1):151-63.

15. Santosh P, Venugopl R, Nilakash AS, Kunjbihari S, Mangala L. Antidepressant activity of methanolic extract of Passiflora foetida leaves in mice. Int J Pharm Pharm Sci 2011;3(1):112-5.

16. Song C, Leonard B. The olfactory bulbectomised rat as a model of depression. Neurosci Biobehav Rev 2005;29(4):627-47.

17. Kashmira G, Mayuri L. Rodent antidepressant models in neuropsychopharmacology: A laboratory prospective. Int J Res Pharm Sci $2012 ; 4(1): 21-43$

18. Heim C, Nemeroff CB. The role of childhood trauma in the neurobiology of mood and anxiety disorders: Preclinical and clinical studies. Biol Psychiatry 2009;49:1023-39.

19. Berton O, McClung CA, Dileone RJ, Krishnan V, Renthal W, Russo SJ, et al. Essential role of BDNF in the mesolimbic dopamine pathway in social defeat stress. Science 2006;311(5762):864-8

20. Meerlo P, Overkamp GJ, Daan S, Van Den Hoofdakker RH, Koolhaas JM. Changes in behaviour and body weight following a single or double social defeat in rats. Stress 1996;1(1):21-32.

21. Bohus B, Koolhaas JM, Heijnen CJ, Boer O. Immunological responses to social stress: Dependence on social environment and coping abilities. Neuropsychobiology 1993;28(1-2):95-9.

22. Buwalda B, de Boer SF, Schmidt ED, Felszeghy K, Nyakas C, Sgoifo A, et al. Long-lasting deficient dexamethasone suppression of hypothalamic-pituitary-adrenocortical activation following peripheral CRF challenge in socially defeated rats. J Neuroendocrinol 1999;11(7):513-20.

23. Krishnan V, Han MH, Graham DL, Berton O, Renthal W, Russo SJ, et al. Molecular adaptations underlying susceptibility and resistance to social defeat in brain reward regions. Cell 2007;131(2):391-404.

24. Willner P. Chronic mild stress (CMS) revisited: Consistency and behavioural-neurobiological concordance in the effects of CMS. Neuropsychobiology 2005;52(2):90-110.

25. Broekkamp C. Predictive validity and the robustness criterion for animal models. Psychopharmacology 1997;134(4):341-3.

26. Kong H, Sha LL, Fan Y, Xiao M, Ding JH, Wu J, et al. Requirement 
of AQP4 for antidepressive efficiency of fluoxetine: Implication in adult hippocampal neurogenesis. Neuropsychopharmacology 2009;34(5):1263-76.

27. Pryce CR, Rüedi-Bettschen D, Dettling AC, Weston A, Russig H, Ferger $\mathrm{B}$, et al. Long-term effects of early-life environmental manipulations in rodents and primates: Potential animal models in depression research. Neurosci Biobehav Rev 2005;29(4-5):649-74.

28. Heim C, Newport DJ, Bonsall R, Miller AH, Nemeroff CB. Altered pituitry-adrenal axis responses to provocative challenge tests in adult survivors of childhood abuse. Am J Psychiatry 2003;1(3):282-9.

29. Kendler KS, Gardner CO, Prescott CA. Toward a comprehensive developmental model for major depression in women. Am J Psychiatry 2002;159(7):1133-45.

30. Zhang TY, Bagot R, Parent C, Nesbitt C, Bredy TW, Caldji C, et al. Maternal programming of defensive responses through sustained effects on gene expression. Biol Psychiatry 2006;73(1):72-89.

31. Ladd CO, Huot RL, Thrivikraman KV, Nemeroff CB, Meaney MJ, Plotsky PM. Long-term behavioral and neuroendocrine adaptations to adverse early experience. Prog Brain Res 2000;122:81-103.

32. Levine $\mathrm{S}$. Infantile experience and resistance to physiological stress. Science 1957;126(3270):405.

33. Alonso SJ, Arevalo R, Afonso D, Rodríguez M. Effects of maternal stress during pregnancy on forced swimming test behavior of the offspring. Physiol Behav 1991;50(3):511-7.

34. Maccari S, Darnaudery M, Morley-Fletcher S, Zuena AR, Cinque C, Van Reeth O. Prenatal stress and long-term consequences: Implications of glucocorticoid hormones. Neurosci Biobehav Rev 2003;27(1-2):119-27.

35. McCormick CM, Smythe JW, Sharma S, Meaney MJ. Sex-specific effects of prenatal stress on hypothalamic-pituitary-adrenal responses to stress and brain glucocorticoid receptor density in adult rats. Brain Res Dev Brain Res 1995;84(1):55-61.

36. Morilak DA, Frazer A. Antidepressants and brain monoaminergic systems: A dimensional approach to understanding their behavioural effects in depression and anxiety disorders. Int J Neuropsychopharmacol 2004;7(2):193-218.

37. Morley-Fletcher S, Rea M, Maccari S, Laviola G. Environmental enrichment during adolescence reverses the effects of prenatal stress on play behaviour and HPA axis reactivity in rats. Eur J Neurosci 2003;18(12):3367-74.
38. Morley-Fletcher S, Darnaudéry M, Mocaer E, Froger N, Lanfumey L, Laviola $\mathrm{G}$, et al. Chronic treatment with imipramine reverses immobility behaviour, hippocampal corticosteroid receptors and cortical 5-HT(1A) receptor mRNA in prenatally stressed rats. Neuropharmacology 2004;47(6):841-7.

39. Secoli SR, Teixeira NA. Chronic prenatal stress affects development and behavioral depression in rats. Stress 1998;2(4):273-80.

40. Smith JW, Seck1 JR, Evans AT, Costall B, Smythe JW. Gestational stress induces post-partum depression-like behaviour and alters maternal care in rats. Psychoneuroendocrinology 2004;29(2):227-44.

41. Weinstock M. Does prenatal stress impair coping and regulation of hypothalamic-pituitary-adrenal axis? Neurosci Biobehav Rev 1997;21(1):1-10.

42. Weinstock M, Matlina E, Maor GI, Rosen H, McEwen BS. Prenatal stress selectively alters the reactivity of the hypothalamic-pituitary adrenal system in the female rat. Brain Res 1992;595(2):195-200.

43. Ridder S, Chourbaji S, Hellweg R, Urani A, Zacher C, Schmid W, et al. Mice with genetically altered glucocorticoid receptor expression show altered sensitivity for stress-induced depressive reactions. J Neurosci 2005;25(26):6243-50.

44. Aguilera G. Corticotropin releasing hormone, receptor regulation and the stress response. Trends Endocrinol Metab 1998;9(8):329-36.

45. Nielsen CK, Arnt J, Sánchez C. Intracranial self-stimulation and sucrose intake differ as hedonic measures following chronic mild stress: Interstrain and interindividual differences. Behav Brain Res 2000;107(1-2):21-33.

46. Leith NJ, Barrett RJ. Effects of chronic amphetamine or reserpine on self-stimulation responding: Animal model of depression? Psychopharmacology (Berl) 1980;72(1):9-15.

47. Yadav YC, Jain A, Deb L. A review: Neuropharmacological screening techniques for pharmaceuticals. Int J Pharm Pharm Sci 2010;2(2):10-4.

48. Cassens GP, Actor C, Kling M, Schildkraut JJ. Amphetamine withdrawal effects threshold of intracranial self-stimulation. Psychopharmacolgy 1981;73(4):318-22.

49. Samuels B, Leonardo E, Gadient R, Williams A, Zhou J, David DJ, et al. Modeling treatment-resistant depression. Neuropharmacology 2011;61(3):408-13.

50. Hibicke M. Development and Evaluation of an Adolescent Chronic Restraint Stress (ACRS) Protocol to Model Adult Depression in Female Rats. Diss. Mercer University; 2017. 